\title{
EAE Cerebrospinal Fluid Augments In Vitro Phagocytosis and Metabolism of CNS Myelin by Macrophages
}

\author{
M.A. Sommer, L.S. Forno, and M.E. Smith \\ Department of Neurology (M.A.S., M.E.S.) and Pathology (L.S.F.), Veterans Affairs Medical Center, Palo \\ Alto, and Stanford University School of Medicine, Stanford, California
}

Previous studies from this laboratory have shown that CNS myelin is phagocytized and metabolized by cultured rat macrophages to a much larger extent when myelin is pretreated with serum containing antibodies to myelin constituents than when it is left untreated or pretreated with non-specific serum. In this study the effect of cerebrospinal fluid (CSF) from rabbits with experimental allergic encephalomyelitis (EAE) in promoting myelin phagocytosis was examined. Fourteen rabbits were immunized with purified myelin in Freund's complete adjuvant, seven of which developed clinical EAE symptoms. Serum and CSF were collected from EAE and control rabbits, and the CSF was centrifuged to remove cells. Sera and CSF from these rabbits and from Freund's adjuvant-immunized controls and untreated controls were measured for IgG content by radial diffusion assay, their myelin antibody characteristics were analyzed by immunoblots, and the ability of these serum and CSF samples to promote myelin phagocytosis when used for myelin opsonization was examined. The ability of a CSF sample to enhance radioactive myelin uptake and phagocytosis by cultured macrophages as measured by the appearance of radioactive cholesterol ester was linearly proportional to its total IgG titer, and correlated approximately both with clinical symptoms of the animal and the presence of antibody against the myelin constituents myelin basic protein, proteolipid protein, and galactocerebroside. The cholesterol esterification activities of EAE sera correlated to a lesser extent with IgG levels and clinical symptoms. These results suggest a possible role for CSF-localized anti-myelin antibody in demyelination in the CNS by macrophages in EAE, and they encourage further study of the role of CSF antibody in cell-mediated demyelination in multiple sclerosis. (C) 1992 Wiley-Liss, Inc.

Key words: antibody, demyelination, cholesterol ester, IgG, opsonization

\section{INTRODUCTION}

Multiple sclerosis (MS) is a disease of the central nervous system (CNS) characterized by widespread demyelinative lesions. Experimental allergic encephalomyelitis (EAE), which can be induced by immunization with CNS myelin (Laatsch et al., 1962; Raine, 1984a) is considered to be a laboratory model of a demyelinative disease with many similarities to MS. Common features in both EAE and MS include focal CNS myelin destruction with sparing of axons (Raine, 1984b); invasion of the CNS by inflammatory cells from the immune system (Adams and Sidman, 1968); implication of macrophages as active participants in myelin destruction (Lampert and Carpenter, 1965; Lampert, 1967); and oligoclonal IgG bands in the cerebrospinal fluid (CSF) of the majority of animals with EAE (Whitacre et al., 1981) and patients with MS (Johnson and Nelson, 1977; Whitacre et al., 1981).

In electron microscopic (EM) studies macrophages or microglia have been shown to phagocytize myelin at the perimeter of active MS plaques, leaving the axons bare (Prineas, 1975; Prineas and Connell, 1978; Raine, 1984b). As the myelin is lost the macrophages have been shown to accumulate neutral lipids (Prineas, 1975). Uptake of myelin occurs through phagocytosis of large myelin droplets and endocytosis of small fragments attached to coated pits on the macrophage surface, an indication of receptor-mediated uptake (Prineas and Connell, 1978; Epstein et al., 1983; Prineas, 1985). In EAE, macrophages actively strip the myelin lamellae, with the appearance of myelin debris within the macrophage cell body (Lampert and Carpenter, 1965). An increase in cholesterol ester levels in the CNS of both MS and EAE

Received October 28, 1991; revised February 28, 1992; accepted February 28, 1992.

Address reprint requests to Marion E. Smith, Ph.D., Department of Neurology 127A, VA Medical Center, 3801 Miranda Ave., Palo Alto, CA 94304. 
is the result of esterification of myelin cholesterol by phagocytic cells immediately following ingestion of myelin (Maggio et al., 1972; Norton and Cammer, 1984). Little or no CE is found in normal, healthy CNS.

In vitro studies have supported evidence for an anti-myelin antibody role in MS and EAE demyelination (Appel and Bornstein, 1964; Seil et al., 1968; Kim et al., 1970; Raine et al., 1973). Serum from animals with EAE as a result of immunization with whole myelin causes myelin breakdown through complement- and antibodydependent mechanisms (reviewed by Raine, 1984b). Furthermore, others have reported that levels of myelin basic protein serum factors correlate with the course of demyelination in MS (Paterson et al., 1981).

Work in this laboratory has illustrated the ability of EAE serum and isolated anti-myelin antibody to enhance the rate of myelin ingestion and intracellular metabolism by macrophages in vitro (Trotter et al., 1986; Smith and DeJong, 1987; Sadler et al., 1991). This report represents an attempt to progress from studies of demyelination involving only EAE serum by considering the demyelinative properties of the localized immune response that develops within the CNS. Therefore we undertook an investigation of the opsonizing effects of CSF from rabbits with EAE on myelin phagocytosis as measured by the formation of cholesterol ester. The effects of CSF from rabbits with EAE have been correlated with the total CSF IgG concentrations, the amount and variety of antimyelin antibody detected, and the severity of clinical symptoms of the donor animal.

\section{MATERIALS AND METHODS}

\section{Preparation and Collection of CSF and Serum}

Twenty-two female New Zealand white rabbits (2$3 \mathrm{~kg}$ ) were immunized with $6 \mathrm{mg}$ purified and lyophilized guinea pig myelin in $1 \mathrm{ml}$ Freund's adjuvant prepared by addition of $3 \mathrm{mg}$ Mycobacterium tuberculosis H37Ra/ml incomplete Freund's adjuvant (Difco Labs, Detroit, MI). Five control rabbits were immunized with Freund's adjuvant containing $M$. tuberculosis alone (FAC). For CSF collection, rabbits were anesthetized

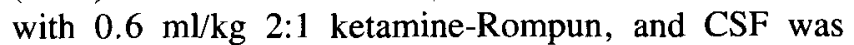
withdrawn by cannulation of the fourth ventricle with a 22-ga, 1.5-in needle (Kusumi and Plouffe, 1979). Samples with any trace of blood were discarded. CSF samples were centrifuged to remove cells and debris, and the clear supernatant fluid was stored at $-70^{\circ} \mathrm{C}$ until ready for use. Blood was collected either by cardiac puncture (terminal) or from the ear (preimmune collection). Preimmune serum and CSF were obtained from randomly selected rabbits 2 days prior to immunization.

\section{Preparation of Myelin and Macrophages}

${ }^{14} \mathrm{C}$-labeled myelin was prepared as described by Trotter et al. (1986). Rat pups, 18 days of age, were injected intracerebrally with $75 \mu \mathrm{Ci}\left[1-{ }^{14} \mathrm{C}\right]$ sodium acetate (New England Nuclear, Boston). The pups were returned to the mother for 3-4 days, then the brains and spinal cords were removed and used for myelin preparation as previously described, using two sucrose gradients with deionized water shocks between (Smith, 1969). The specific activity of the purified myelin was about $450,000 \mathrm{dpm} / \mathrm{mg}$ myelin protein. Two milligram myelin aliquots were frozen at $-70^{\circ} \mathrm{C}$ until ready for use. Thioglycollate-elicited peritoneal macrophages were harvested from 4-6-month-old rats by peritoneal lavage, and prepared as previously described (Trotter et al., 1986). These were allowed to adhere for $2 \mathrm{hr}$ on $60 \mathrm{~mm}$ plastic tissue culture plates in the presence of D-MEM containing 5\% newborn calf serum, then the non-adherent material was washed off, and the cells were cultured overnight in defined medium (N2) (Bottenstein and Sato, 1979). The next morning the cultures were washed with PBS and treated or untreated radioactive myelin suspensions in $4 \mathrm{ml} \mathrm{N} 2$ medium was added to each plate. Myelin was prepared by light sonication in PBS (100 W for $1 \mathrm{~min}$ ), then $50 \mu \mathrm{l}$ test CSF, sera, or PBS was added to $0.10 \mathrm{mg}$ myelin protein. The mixtures were incubated at $4^{\circ} \mathrm{C}$ overnight with shaking before adding to the macrophage cultures. The cultures containing CSF-treated, serum-treated, or untreated myelin were incubated at $37^{\circ} \mathrm{C}$ in $5 \% \mathrm{CO}_{2}$ for $30 \mathrm{hr}$. The medium was aspirated, and the macrophage monolayer was lysed and scraped off using several washes of deionized ice water. The total medium + cells + water was combined and lyophilized.

\section{Lipid Extraction and Separation}

The entire lyophilized sample was reconstituted in $1 \mathrm{ml} \mathrm{H}_{2} \mathrm{O}$ and the lipids were extracted according to Folch et al. (1957). The entire sample was subjected to thin-layer chromatography on silica gel plates using petroleum ether/diethyl ether/acetic acid 8:20:1 v/v/v, visualized with iodine vapor, and identified with reference standards. Lipid-containing areas represented cholesterol ester, triglyceride, free fatty acid, cholesterol, and material remaining at the origin (phospholipid, galactolipid, and residual water-soluble substances). These spots were scraped into scintillation vials and counted in $10 \mathrm{ml}$ scintillation fluid as previously described (Trotter et al., 1986). The amount of radioactive (myelin derived) cholesterol ester and cholesterol present was determined by radioactive measurement. We have determined that approximately $2 / 3$ of the dpm in cholesterol ester is in the cholesterol molecule, with the remaining $1 / 3 \mathrm{dpm}$ resid- 
ing in the fatty acid. Fraction cholesterol esterified was calculated as

$$
\frac{2 / 3 \mathrm{dpm} C E}{2 / 3 \mathrm{dpm} \mathrm{CE}+\mathrm{dpm} \text { cholesterol }}
$$

We used this number multiplied by 100 , the percent cholesterol esterified, to represent the ability of a particular CSF or serum sample to influence macrophage esterification of myelin cholesterol. When normalized by dividing by the particular experiment's mean untreated value of percent cholesterol esterified, a sample's "percentage of untreated activity" could be determined and used for comparison with other samples, either between or within experiments.

\section{Radial Immunodiffusion Assays}

The concentration of IgG in the serum and CSF samples was measured by radial immunodiffusion (Kit \#646001, ICN ImmunoBiologicals, Costa Mesa, CA). Since the CSF IgG levels were comparatively low ( $\leq 100$ mg\%) (Whitacre et al., 1981) a new standard curve for $10 \mathrm{mg} \%$ to $300 \mathrm{mg} \%$ was developed. It was found that a linear fit represented the data very well, as opposed to the usual exponential curve fit for concentrations greater than $300 \mathrm{mg} \%$. Calculations showed an accuracy with this linear regression to within $\pm 10 \mathrm{mg} \%$. Concentrations below $10 \mathrm{mg} \%$ could not be determined with any precision, and are therefore represented as $\leq 10 \mathrm{mg} \%$. The usual exponential fit was used for determining the IgG titers of sera, which were consistently near or higher than $300 \mathrm{mg} \%$.

\section{Immunoblot Analysis}

Immunoblots were performed as qualitative tests for the presence of antibodies toward CNS myelin proteins. For each blot, a purified rat CNS myelin sample was partially delipidated with acetone/ether $1: 1(\mathrm{v} / \mathrm{v})$ and the proteins separated by SDS-PAGE (Laemmli, 1970), then transferred to a nitrocellulose sheet using a current of $300 \mathrm{~mA}$ for $24 \mathrm{~h}$ (Towbin et al., 1979). The sheet was cut into strips, and each CSF, serum, or control sample was incubated with a strip overnight. Peroxidase-conjugated anti-rabbit $\operatorname{IgG}$ was used to detect the presence of antibodies to the myelin proteins (Sternberger et al., 1970). Galactocerebroside strips were also made by immersing one end of a nitrocellulose strip into a $1 \mathrm{mg} / \mathrm{ml}$ solution of galactocerebroside, and the other end into a 1 $\mathrm{mg} / \mathrm{ml}$ solution of sphingomyelin as a control. After drying, the strips were incubated with the CSF, serum, and control samples overnight and visualized in the same manner as the Western blots.

\section{RESULTS \\ Rabbits: Clinical Symptoms}

Of the 22 rabbits immunized with purified myelin in Freund's adjuvant, 11 showed clinical symptoms of EAE, including weight loss, incontinence, and hindquarter paralysis. When death appeared imminent as indicated by extreme paralysis and labored breathing, serum and CSF were collected before euthanasia. No clinical symptoms were observed in the remaining 11 myelinimmunized nor the 5 FAC rabbits; blood and CSF were collected from most of them at 37-42 days after immunization. Two non-symptomatic and one FAC rabbit were continued until day 63 , after which time symptoms did appear in one myelin-immunized rabbit. One other FAC and two myelin-immunized animals were continued until day 95, and remained asymptomatic throughout.

The brain and spinal cord of most of the animals were dissected out following sacrifice, and histological examination showed extensive demyelinative lesions and infiltration of mononuclear cells in the CNS of all myelin-immunized animals inspected, whether or not they had exhibited clinical symptoms. Histological examination of the tissues revealed characteristic signs of EAE, including perivenous invasion of inflammatory cells and areas of ongoing demyelination (Fig. 1). No pathological abnormalities in the CNS of FAC animals were seen.

\section{Collection of Cerebrospinal Fluid and Serum}

Because of blood contamination of a number of the earlier CSF specimens, some were considered unusable. The resultant study is based on CSF samples from 3 preimmune, 7 clinically symptomatic myelin-immunized, 7 non-symptomatic myelin-immunized, and 3 FAC rabbits. Each successfully recovered CSF sample consisted of between 0.5 and $2.0 \mathrm{ml}$ clear fluid. Also, about $15-20 \mathrm{ml}$ blood was successfully collected from each rabbit.

\section{Measurement of Esterification Activity}

Results of a single typical experiment using matched sets of CSF and serum from the same rabbit are shown on Table I. Multiple assays of the CSF samples were performed when possible, but the small volumes of CSF collected most often prohibited this. At least two untreated controls were run with each experiment to enable the calculation of the level of significance of deviation from the control. The radioactivity of cholesterol ester expressed as dpm, percent of myelin cholesterol esterified, and the ratio of treated myelin/untreated myelin (percentage of untreated activity) was generally higher when the myelin was pretreated with CSF from rabbits with clinical symptoms than that from those with no clinical symptoms, the FAC or from the preimmune 

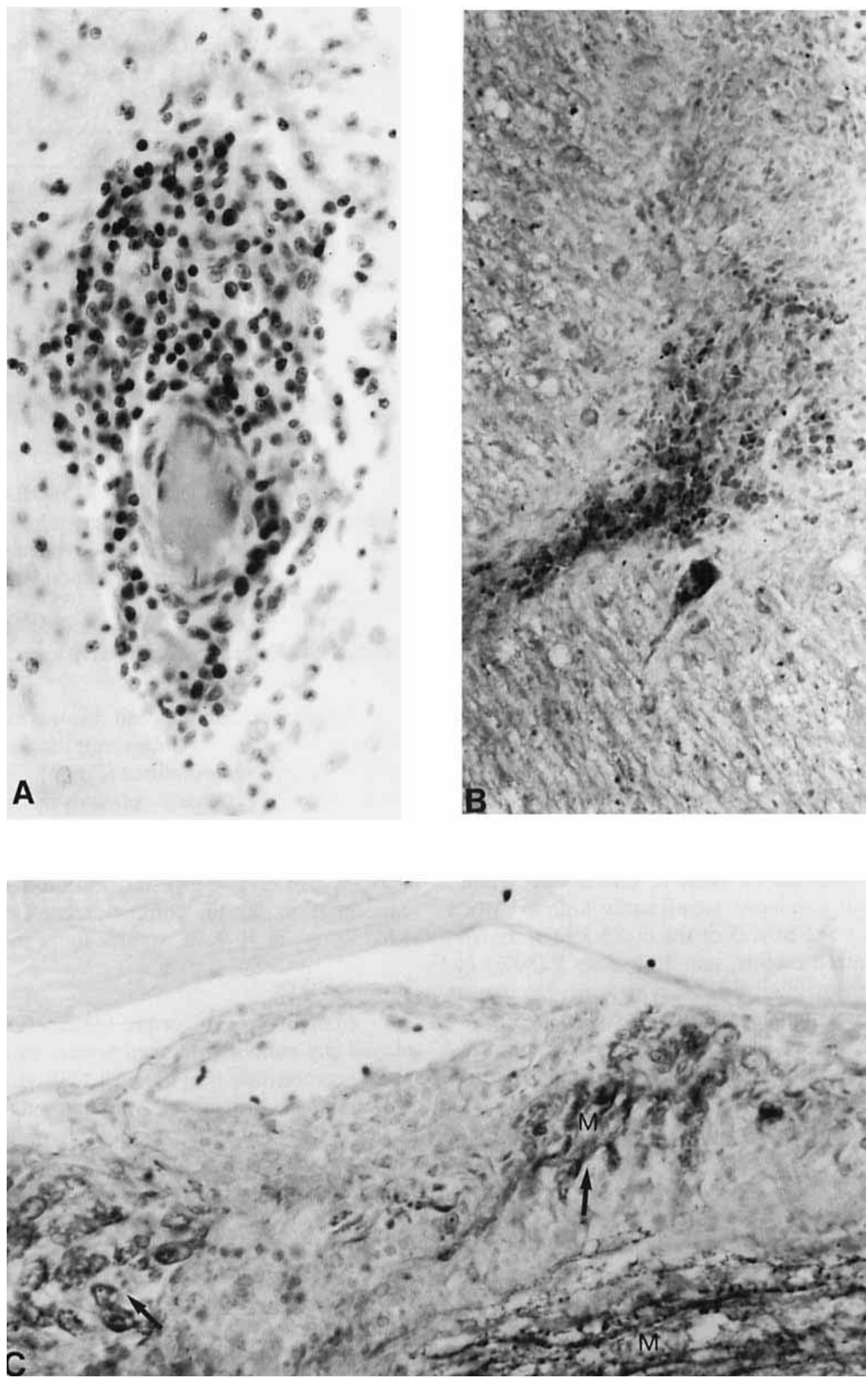

Fig. 1. Lesions in rabbits with acute paralytic symptoms. A: Perivascular cuff in the CNS of rabbit with acute EAE. Mononuclear cells in the perivascular space are invading the parenchyma. This lesion is typical of many found throughout the CNS of affected rabbits. $H$ \& $E$, original magnification, $\times 540$. B: Lesion in brain stem of rabbit 17 . The area of acute invasion of mononuclear cells is accompanied by demyelination. Luxol fast blue-cresyl violet, original magnification, $\times 470$. C: Subpial demyelination in the spinal cord of rabbit 12. Active phagocytosis of myelin is marked by arrows; $\mathbf{M}=$ myelin. Luxol fast blue-cresyl violet, original magnification, $\times 470$. 
TABLE I. Radioactivity of Cholesterol Ester (CE) after $30 \mathrm{hr}$ Incubation of Macrophages With Radioactive Myelin Opsonized With CSF or Serum From Rabbits With (EAE +) or Without Symptoms (EAE -) of EAE Compared With Freund's Adjuvant Injected (FAC) or Preimmune Controls*

\begin{tabular}{lccccccc}
\hline & \multicolumn{3}{c}{ CSF } & & \multicolumn{2}{c}{ Serum } \\
\cline { 2 - 3 } \cline { 6 - 8 } Rabbit No. & dpm & \% Esterified & Ratio & dpm & \% Esterified & Ratio \\
\hline 12 (EAE +) & 2,109 & 30.9 & 2.18 & 2,160 & 36.2 & 3.09 \\
13 (EAE +) & 1,512 & 22.0 & 1.55 & 2,275 & 39.1 & 3.34 \\
17 (EAE +) & 1,534 & 23.6 & 1.66 & 1,400 & 24.8 & 2.12 \\
16 (EAE -) & 572 & 9.0 & 0.63 & 1,685 & 29.5 & 2.52 \\
15 (FAC) & 524 & 7.8 & 0.55 & 623 & 13.2 & 1.13 \\
Preimmune & 553 & 9.0 & 0.63 & & 802 & 18.2 & 1.55 \\
Untreated & 846 & 14.2 & & 758 & 11.7 & \\
\hline
\end{tabular}

*Percent esterified is calculated as described in Methods; ratio is the number obtained by dividing the percent esterified by that of the untreated myelin value. Results of a typical experiment.

rabbits. All sera from myelin-immunized rabbits, on the other hand, stimulated cholesterol esterification to a greater degree than the FAC and preimmune sera (typical example shown on Table I).

The results of the experiments using all of the CSF samples are ranked in order of mean relative activity in Figure 2. The CSF samples from all rabbits except one (No. 14) showing clinical symptoms augmented the cholesterol esterification compared to the saline control. Most of the FAC and preimmune samples, on the other hand, yielded esterification values close to or below the level of the saline value. CSF from clinical asymptomatic myelin-injected animals were divided, with esterification values on both sides of the untreated value. These results are summarized on Table II. Of the CSF samples that consistently produced significantly high esterification activities ( $>2$ SD), 5 of the $6(83.3 \%)$ were from myelin-immunized rabbits, and 4 of these $5(80 \%)$ had moderate to severe clinical EAE symptoms. In contrast, all 3 of the preimmune CSF samples, and 2 of the 3 (66.7\%) FAC samples, had significantly low esterification activity. Four of the $14(28.6 \%)$ CSF samples from myelin-immunized rabbits had significantly low esterification activity, but none of these animals had exhibited clinical EAE symptoms. The 5 remaining CSF samples had activities that deviated nonsignificantly $(<2$ SD) from mean untreated activity; these were all obtained from myelin-immunized rabbits, both with and wihout clinical EAE symptoms.

\section{IgG Concentrations in the CSF and Serum Samples}

The total IgG in each CSF and serum sample as measured by radial immunodiffusion (RID) assay is compared with the clinical condition of each rabbit at time of sample collection in Figure 3. All CSF samples had IgG levels less than $100 \mathrm{mg} \%$, below the exponential portion of the standard curve, but within the linear region. Some CSF samples exhibited rings in RID that were detectable, but less than $10 \mathrm{mg} \%$. Others with no visible ring whatsoever were termed "not detectable." All serum sample IgG levels were near or greater than $300 \mathrm{mg} \%$ and fell within the exponential region of the standard curve.

\section{Analysis of Esterification Activity vs. IgG Concentration}

The correlation between mean normalized esterification activity and IgG concentration of the CSF and serum samples was examined (Fig. 4). The CSF samples displayed a direct linear relationship between activity and IgG concentration, with a correlation coefficient $R$ $=0.60$, significant at the $99 \%$ level. Serum samples also showed increased esterification activity with IgG concentration, but the correlation coefficient was somewhat lower, $\mathrm{R}=0.50$, significant at the $95 \%$ level.

\section{Immunoblots}

None of the FAC or pre-immune CSF samples displayed any antibody directed toward myelin proteins or galactocerebroside (Fig. 5). All CSF samples from myelin-immunized rabbits showed antibody toward myelin basic protein. Some had antibody to proteolipid protein, and a few displayed high molecular weight bands of unknown identity, possibly anti-2' 3 'cyclic nucleotide $3^{\prime}$ phosphohydrolase (CNP-ase). Six of seven CSFs from the rabbits with clinical EAE symptoms showed definite anti-GC antibody, while two out of seven from nonsymptomatic myelin-immunized rabbits were faintly positive for anti-GC.

\section{DISCUSSION}

We have previously demonstrated that antiserum to CNS myelin, PNS myelin, myelin basic protein, and galactocerebroside when complexed with myelin greatly augments myelin phagocytosis and metabolism (produc- 


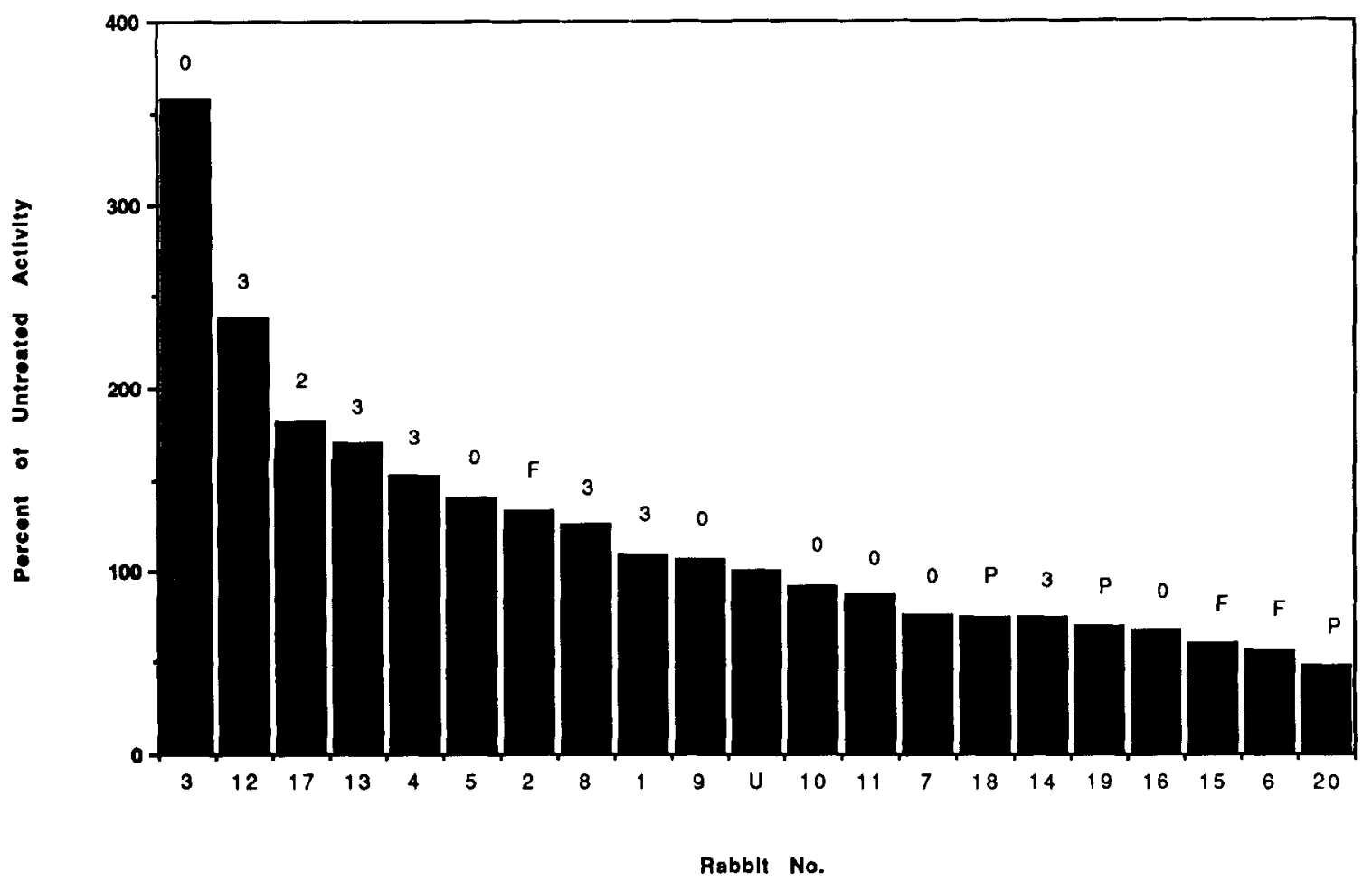

Fig. 2. Mean normalized esterification activities of each CSF sample in descending order. Rabbit identification number on abscissa, symptomatic condition rating of each rabbit at CSF collection noted on graph: $0=$ no symptoms; 1 = mild ataxia; $2=$ partial paralysis; $3=$ severe hindquarters paralysis. $\mathrm{F}=$
Freund's adjuvant control; $\mathrm{P}=$ preimmune control; $\mathrm{U}=$ untreated saline control. Except for one FAC sample, all of the samples with higher esterification activity than saline were from myelin-immunized rabbits, and most of those were from clinically symptomatic EAE animals.

TABLE II. Pooled Results of the Four Experiments, Sorted by Condition of Animal at Time of CSF Collection*

\begin{tabular}{lccc}
\hline Rabbit condition at CSF draw & $\begin{array}{c}\text { Samples } \\
\text { with significantly } \\
\text { high activity }\end{array}$ & $\begin{array}{c}\text { Samples with } \\
\text { non-significant } \\
\text { activity }\end{array}$ & $\begin{array}{c}\text { Samples } \\
\text { with significantly } \\
\text { low activity }\end{array}$ \\
\hline Myelin-immunized, symptoms $>0$ & $4 / 7(57.1 \%)$ & $3 / 7(42.9 \%)$ & $0 / 7(0.0 \%)$ \\
Myelin-immunized, symptoms $=0$ & $1 / 7(14.3 \%)$ & $2 / 7(28.6 \%)$ & $4 / 7(57.1 \%)$ \\
FAC & $1 / 3(33.3 \%)$ & $0 / 3(0.0 \%)$ & $2 / 3(66.7 \%)$ \\
Preimmune & $0 / 3(0.0 \%)$ & $0 / 3(0.0 \%)$ & $3 / 3(100.0 \%)$ \\
\hline
\end{tabular}

*The probability that a CSF sample will significantly augment myelin uptake and metabolism by macrophages in vitro depends not only upon whether the donor animal was myelin-immunized, but also whether the animal developed clinical EAE symptoms. Symptom rating scale as in Figure 2. A statistically significant activity is defined as one that is different from mean saline activity by at least 2 standard deviations (SD); sample activities within 2 SD of mean saline activity are deemed non-significant.

tion of cholesterol ester and triglyceride by macrophages in vitro) (Trotter et al., 1986; Smith et al., 1990). Serum from Lewis rats drawn 10-95 days after immunization with guinea pig myelin also stimulates myelin phagocytosis (Smith and DeJong, 1987; Sadler et al., 1991). The level of antibody and the degree of augmentation of myelin destruction increase up to 25-29 days after immunization, then decrease somewhat, but in general, both remain high at least until 95 days after immunization
(Sadler et al., 1991). The active factor in the sera has been shown to consist of IgG alone. Decomplemented sera are as active in most cases as intact sera, and IgG purified on affinity columns retains the full opsonizing activity. Goldenberg et al. (1989) have also reported increased macrophage binding to myelin opsonized by antibodies to myelin basic protein and galactocerebroside. In cell-mediated demyelinating disease, $\mathrm{T}$ cells, $\mathrm{B}$ cells, and macrophages enter the brain parenchyma. 

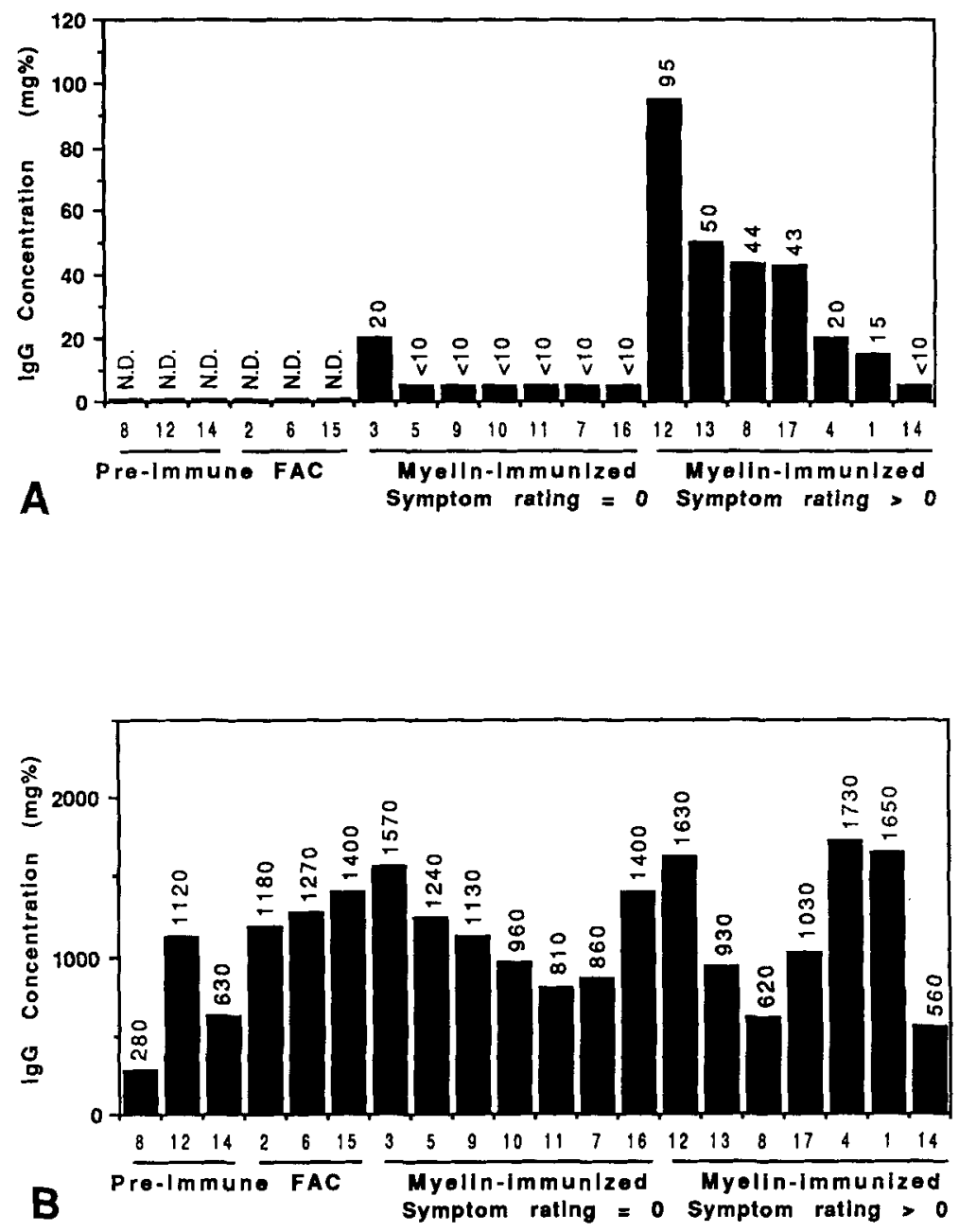

Fig. 3. Total IgG concentration in CSF and serum samples compared with clinical symptoms for each rabbit. Rabbit identification number and clinical symptom groupings on abscissa.
Symptoms rating as in Figure 2. A: IgG concentration in CSF of each animal, all $\pm 10 \mathrm{mg} \%$. B: IgG concentrations in serum of each animal, all approximately $\pm 50 \mathrm{mg} \%$.
With the breakdown of the blood-brain barrier, serum factors, including antibody, formed from the immunization mechanisms would be expected to come in contact with CNS tissue. B cells activated either outside or within the CNS may produce antibody to the immunizing myelin. The CSF would be expected to reflect the state of the inflammatory events, and indeed, oligoclonal bands of IgG have long been known to occur in MS, and more recently have been found in CSF of EAE guinea pigs and rabbits (Whitacre et al., 1982; livanainen et al., 1982; Mehta et al., 1987). In view of the effect of antimyelin IgG on myelin phagocytosis, it was of interest to determine whether sufficient amounts occur within the CNS in demyelinating disease to augment this activity.

Considering the large difference in IgG concentrations between serum and CSF, it was of utmost importance to exclude the slightest trace of blood in the CSF samples. Thus it was necessary to discard a number of the samples, especially during the process of learning to draw CSF from rabbits. The successful collection of blood-free CSF samples used in this study is illustrated by the negligible quantities of IgG present in the preimmune and FAC CSF samples compared to the high IgG in their sera.

CSF and serum samples were collected from clinically symptomatic EAE animals as late in the disease as possible. Myelin-immunized, but non-symptomatic animals were sometimes maintained longer than the usual 40 days, in hopes that they would eventually develop symptoms (one animal developed moderate paralysis at day 60 , and collection of serum and CSF was performed on day 63 ). We discovered no apparent correlation between day of sacrifice and the demyelinative properties of the CSF; for example, three of the rabbits had com- 

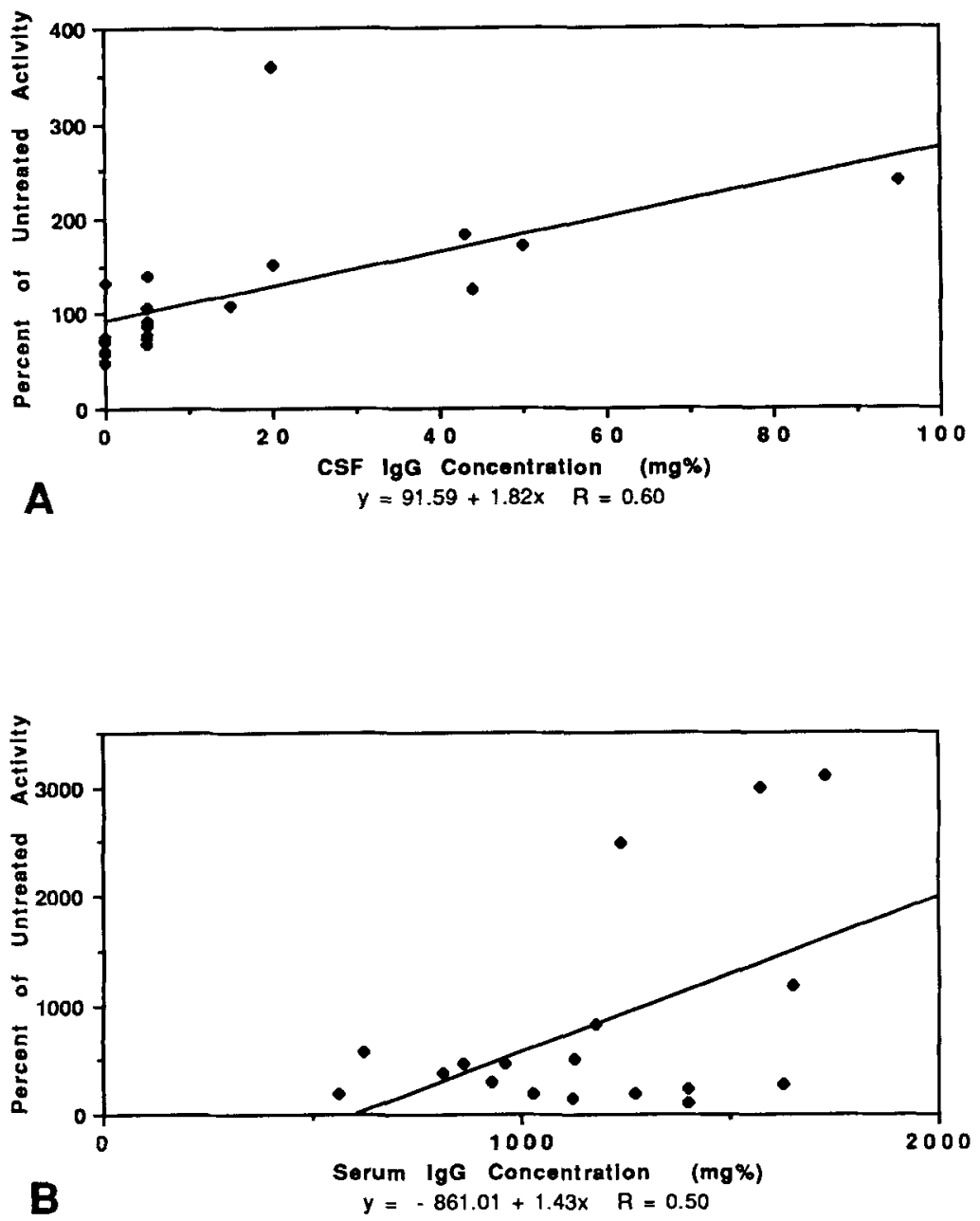

Fig. 4. Correlation between normalized mean esterification activity of each sample and its total IgG concentration. $<10$ $\mathrm{mg} \%$ represented as $5 \mathrm{mg} \%$; N.D. (not detected) as $0 \mathrm{mg} \%$. A: Linear fit to the CSF samples. A linear relationship exists between a CSF sample's IgG concentration and its ability to enhance macrophage uptake and metabolism of myelin despite one anomalous datum (rabbit 3 ). $R=0.60, n=20$, significant at the $99 \%$ confidence level. B: Linear fit to the serum samples, preimmune serum samples 18 and 20 not included (data unavailable). Increasing activity with IgG concentration is shown ( $\mathrm{R}=0.50$, significant at the $95 \%$ confidence level). parable esterification activities $(170,151$, and $140 \%$ of untreated) after being sacrificed at days 17, 45, and 95 days post-immunization, respectively. In additional experiments the CSF was concentrated to double the amount used to opsonize myelin. In most cases, this did not change the amount of cholesterol esterification (results not shown).

Since previous studies suggested that IgG is the main factor in EAE serum-augmented phagocytosis and metabolism of myelin by macrophages in vitro, and EAE CSF has IgG levels much lower than EAE serum, we were skeptical that non-concentrated CSF would have any effect in our culture system. It was apparent, however, that CSF from rabbits immunized with myelin and adjuvant did augment the phagocytosis and metabolism of CNS myelin by cultured macrophages, as demonstrated. As shown in Table II, five of the myelin-immunized animals consistently had CSF esterification activities significantly greater than that of the untreated (saline) control, and 4/5 of these donor animals had exhibited moderate to severe paralysis and other clinical EAE symptoms by the time of CSF collection. Four of the myelin-immunized animals had CSF activities significantly lower than that of saline, but no EAE symptoms had ever been detected in these rabbits. Only one of the six control samples, from an FAC rabbit, had significantly high activity; the other 2 FAC samples and all 3 of the preimmune samples had significantly less activity 


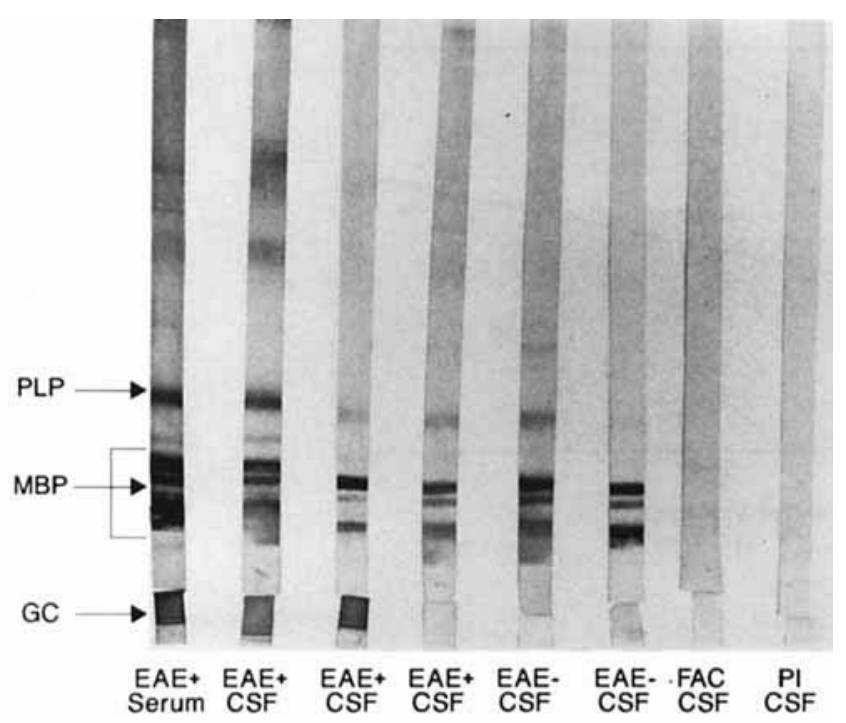

Fig. 5. Immunoblots of CNS myelin proteins. The delipidated myelin proteins were separated by SDS-polyacrylamide gel electrophoresis and electroblotted onto nylon membranes. The strips were immunostained with serum or CSF from rabbits as noted. Nylon strips were also dipped into galactocerebroside solution and immunostained. Two exceptional cases are included: the only CSF sample from the set of 7 clinically EAE rabbits that did not exhibit GC antibody, and one of two CSF samples from the set of 7 clinically asymptomatic rabbit that stained (faintly) for GC. PLP = proteolipid protein; $\mathrm{MBP}=$ the three myelin basic protein bands; $\mathrm{GC}=$ galactocerebroside. EAE serum was diluted 1:250; CSF, 1:50.

than saline. Some inhibitory property may be present in these CSF samples to repress phagocytosis.

These results suggest that the esterification activity of a CSF sample correlates with an animal's exposure to myelin and magnitude of its resultant clinical EAE symptoms, but what property of the CSF might be responsible for this relationship? A growing body of evidence that includes the presence of oligoclonal IgG bands in EAE $\mathrm{CSF}$, the selective stripping of myelin, the presence of $\mathrm{Fc}$ receptors on macrophages, the identification of myelin attachment to coated pits on macrophages in EAE (Epstein et al., 1983) and the illustration of capping of surface IgG on macrophages engaged in demyelination in MS (Prineas and Graham, 1981) have suggested a role for myelin antibody in macrophage breakdown of myelin in MS and EAE. Evidence from our in vitro model indicates a strong relationship between IgG levels and the ability of a CSF sample to augment myelin phagocytosis and metabolism by macrophages. Although preimmune and FAC IgG levels in CSF were completely non-detectable using radial immunodiffusion (Fig. 2a), IgG was detected in every myelin-immunized sample. Of these, the seven non-symptomatic rabbits had low but detect- able IgG titers of about $10 \mathrm{mg} \%$ with the exception of rabbit 3 at $20 \mathrm{mg} \%$. Onset of clinical symptoms was almost always associated with higher IgG concentrations. IgG levels of all seven clinically symptomatic EAE CSF samples, except for that from rabbit 14, were greater than $10 \mathrm{mg} \%$, with the highest ranging up to 95 $\mathrm{mg} \%$. A direct relationship could be shown between the esterification activity and the CSF IgG concentration. Rabbit 3 provides an apparently anomalous datum: with this animal included, the linear fit is $R=0.60$, but when it is omitted, the remaining points are linear with $\mathrm{R}=0.86$. With $\mathrm{N}=20, \mathrm{R}>0.559$ exceeds the $99 \%$ confidence level of linear fit.

Unlike the CSFs, all sera, including preimmune and FAC had esterification activities higher than that of saline (partial data shown on Table I). Of 17 serum samples from myelin-immunized rabbits, 12 samples (71\%) had activities higher than the highest control. Total IgG concentration, however, did not correspond well with clinical symptoms (Fig. 3b). In addition, there was no obvious relationship between a rabbit's CSF and serum IgG titers. The correlation between esterification activity and IgG concentration in the serum samples could be approximated with linear regression analysis with a correlation coefficient of 0.50 , significant at the $95 \%$ level $(\mathrm{N}=18)$.

RID measured total IgG in a sample without discriminating between different antibody specificities. Using immunoblot analysis on CSF from myelin-immunized rabbits we found anti-myelin antibndies directed toward the protein constituents MBP, PLP, and perhaps the CNP-ase. Dot blots of GC revealed the presence of anti-GC antibody in some of the rabbits. All serum samples from myelin-immunized rabbits showed antibody specificity for the entire myelin protein spectrum as well as for GC. No FAC, preimmune CSF, nor serum samples showed the presence of antibody toward any myelin constituents. Within the myelin-immunized set of rabbits, those which developed clinical EAE symptoms displayed the presence of anti-GC antibody in CSF more frequently (6/7) than in CSF from non-symptomatic animal $(2 / 7)$; this was the only direct correlation we observed between the expression of a particular antibody specificity and development of clinical EAE symptoms.

Although the CSF samples drawn for our study clearly showed the presence of antimyelin antibodies, Whitacre et al. (1982) could not demonstrate any specificity to neural antigens in oligoclonal bands of rabbits with clinical symptoms of EAE. On the other hand, Mehta et al. (1987) showed specificity of IgG bands against myelin proteins in chronic relapsing EAE in guinea pigs. Anti-GC antibodies have previously been reported in CSF of rabbits with acute EAE (Kuwert and Niedieck, 1965). Our success in identifying antibody 
against myelin proteins, even at the 1:50 dilution of the CSF required for the assay, confirms the presence of antibodies to myelin constituents in CSF of EAE animals.

The relationship between the specificities of IgG oligoclonal bands in CSF of MS patients and myelin constituents has been explored by many investigators. Antibody toward MBP was found most frequently (e.g., Panitch et al., 1980; Warren and Catz, 1986; 1987). The level of anti-MBP appears to be present in excess during exacerbation of MS, but during remission, or in the chronic progressive state, the antibody is bound. Similarly, Kasai et al. (1986) found IgG antibodies against GM4 and galactocerebroside to be present in CSF of MS patients, and a significant proportion of them existed as immune complexes. Other have identified antibody to myelin-associate glycoprotein in CSF of MS patients (Sato et al., 1987; Wajgt and Gorny, 1983; Moller et al., 1989). The specificity, however, of the majority of oligoclonal IgG in MS CSF is still undetermined, and a portion may be attributed to non-specific B cell activation within the CSF.

The interrelations observed in this study between the esterification activity of a CSF sample, its total IgG concentration, the presence and variety of anti-myelin antibodies, and the animals' clinical EAE symptoms are relevant to the idea that humoral factors are involved in macrophage-mediated demyelination in EAE. The amount and specificity of IgG in the CSF undoubtedly reflects the degree of acute immunological and destructive activity proceeding in the CNS. Thus, the higher levels of IgG in CSF may reflect the leakage of antibody from the peripheral blood with the breakdown of the blood-brain barrier and/or the presence of sensitized B cells actively producing CNS antibody within the CNS or the CSF. Whether this repository of antibody may act as an opsonizing agent for further demyelinative activity is unknown.

\section{ACKNOWLEDGMENTS}

The authors are grateful to Rober H. Sadler for valuable advice, to F. Paul Somera for technical assistance, and to Dr. Rosemary Broome for assistance with the CSF withdrawals in the rabbit. This work was supported by The Department of Veterans Affairs, by grant NS-02785 (Javits Neuroscience Award Grant) from the NIH, and by the Multiple Sclerosis Society.

\section{REFERENCES}

Adams RD, Sidman RL (1968): Demyelinative diseases. In Adams RD, Sidman RL (eds): "An Introduction to Neuropathology." New York: McGraw-Hill, pp 149-170.
Appel SH, Bornstein MB (1964): The application of tissue culture to the study of experimental "allergic" encephalomyelitis. II. Serum factors responsible for demyelination. J Exp Med 119: 303-313.

Bottenstein JE, Sato GH (1979): Growth of a rat neuroblastoma line in serum-free supplemented medium. Proc Natl Acad Sci USA 76:514-517.

Epstein LG, Prineas JW, Raine CS (1983): Attachment of myelin to coated pits on macrophages in experimental allergic encephalomyelitis. J. Neurol Sci 61:341-348.

Folch J, Lees M, Sloane Stanley GH (1957): A simple method for the isolation and purification of total lipids from animal tissue. $\mathrm{J}$ Biol Chem 22:497-509.

Goldenberg PZ, Kwon EE, Benjamins JA, Whitaker JN, Quarles RH Prineas JW (1989): Opsonization of normal myelin by antimyelin antibodies and normal serum. J Neuroimmunol 23:157166.

Iivanainen M, Driscoll B, Richert J, Leon M, Chu A, Kies M, Brown B, Wallen W, Madden D, and Sever J. (1982): Oligoclonal IgG in the cerebrospinal fluid of guinea pigs with experimental allergic encephalomyelitis. Proc Soc Exptl Biol Med 171:272275.

Johnson KP, Nelson BJ (1977): Multiple sclerosis: Diagnostic usefulness of cerebrospinal fluid. Ann Neurol 2:425-431.

Kasai N, Pachner AR, Yu RK (1986): Anti-glycolipid antibodies and their immune complexes in MS. J Neurol Sci 75:33-42.

Kim SU, Murray MR, Tourtellotte WW, Parker JA (1970): Demonstration in tissue culture of myelinotoxicity in cerebrospinal fluid and brain extracts from multiple sclerosis patients. J Neuropathol Exp Neurol 29:420-431.

Kusumi RK, Plouffe JF (1979): A safe and simple technique for obtaining cerebrospinal from rabbits. Lab Anim Sci 29:681-682.

Kuwert E, Niedieck B (1965): Anti-cerebroside antibodies in cerebrospinal fluid of rabbits with experimental 'allergic' encephalomyelitis. Nature 207:991-992.

Laatsch RH, Kies MW, Gordon S, Alvord EC, Jr (1962): The encephalomyelitic activity of myelin isolated by ultracentrifugation. J Exp Med 115:777-788.

Laemmli UK (1970): Cleavage of structural proteins during the assembly of the head of bacteriophage T4. Nature 227:680-685.

Lampert P (1967): Electron microscopic studies on ordinary and hyperacute experimental allergic encephalomyelitis. Acta Neuropathol 9:99-126.

Lampert P, Carpenter S (1965): Electron microscopic studies on the vascular permeability and the mechanism of demyelination in experimental allergic encephalomyelitis. J Neuropathol Exp Neurol 24:11-24

Maggio B, Cumar FA, Maccioni HJ (1972): Lipid content in brain and spinal cord during experimental allergic encephalomyelitis in rats. J Neurochem 19:1031-1037.

Mehta PD, Patrick BA, Mehta SP, Wisniewski HM (1987): Specificity of oligoclonal IgG bands against myelin proteins in chronic relapsing EAE in guinea pigs. $J$ Immunol 138:746-751.

Moller JR, Johnson D, Brady RO, Tourtellotte WW, Quarles RH (1989): Antibodies to myelin-associated glycoprotein (MAG) in the cerebrospinal fluid of multiple sclerosis patients. J Neuroimmunol 22:55-61.

Norton WT, Cammer W (1984): Chemical pathology of diseases involving myelin. In Morell P (ed): "Myelin." New York: Plenum Press, pp 369-403.

Panitch HS, Hooper CJ, Johnson KP (1980): CSF antibody to myelin basic protein. Measurement in patients with multiple sclerosis and subacute sclerosing parencephalitis. Arch Neurol 37:206209. 
Patterson PY, Day ED, Whitacre CC (1981): Neuroimmunologic diseases: Effector cell responses and immunoregulatory mechanisms. Immunol Rev 55:89-120.

Prineas JW (1975): Pathology of the early lesion in multiple sclerosis: Hum Pathol 6:531-554.

Prineas JW (1985): The neuropathology of multiple sclerosis. In Koetsier, JC (ed): "Handbook of Clinical Neurology, Vol 3 (47) Demyelinating Diseases." Amsterdam: Elsevier Science Publishers, pp 213-257.

Prineas JW, Connell F (1978): The fine structure of chronically active multiple sclerosis plaques. Neurology 28:68-75.

Prineas JW, Graham JS (1981): Multiple sclerosis: capping of surface immunoglobulin $\mathrm{G}$ on macrophages engaged in myelin breakdown. Ann Neurol 10:149-158.

Raine CS (1984a): Biology of disease. Analysis of autoimmune demyelination: its impact upon multiple sclerosis. Lab Invest 50: $608-635$.

Raine CS (1984b): Demyelinating diseases. In Davis RL, Robertson DM (eds): "Textbook of Neuropathology." Baltimore: Williams \& Wilkins, pp 468-516.

Raine CS, Hummelgard A, Swanson E, Bornstein MB (1973): Multiple sclerosis: Serum-induced demyelination in vitro. A light and electron microscopic study. J Neurol Sci 20:127-148.

Sadler RH, Sommer MA, Forno LS, Smith ME (1991). Induction of anti-myelin antibodies in EAE and their possible role in demyelination. J Neurosci Res 30:616-624.

Sato S, Baba H, Inuzuka T, Miyatake T (1986). Anti-myelin-associated glycoprotein antibody in sera from patients with demyelinating diseases. Acta Neurol Scand 74:115-120.

Seil FJ, Falk GA, Kies MW, Alvord EC Jr (1968): The in vitro demyelinating activity of sera from guinea pigs sensitized with whole CNS and with purified encephalitogen. Exp Neurol 22: 545-555.

Smith ME (1969): An in vitro system for the study of myelin synthesis. J Neurochem 16:83-92.

Smith ME, DeJong LJ (1987): Antibody to myelin constituents: a possible factor in induction of cell-mediated demyelination. Neurochem Res 12:167-172.
Smith ME, Sadler RH, Dyer C, Benjamins JA, Yu ACH (1990): Phagocytosis of peripheral nerve myelin in vitro. Effect of antibody. J Neurosci Res 27:298-306.

Sternberger LA, Hardy PH Jr, Cuculis JJ, Meyer HG (1970): The unlabeled antibody enzyme method of immunohistochemistry. Preparation and properties of soluble antigen-antibody complex (horseradish peroxidase-antihorseradish peroxidase) and its use in identification of spirochetes. J Histochem Cytochem 18: 315-333.

Towbin H, Staehelin T, Gordon J (1979): Electrophoretic transfer of proteins from polyacrylamide gels to nitrocellulose sheets: Procedure and some applications. Proc Natl Acad Sci USA 76: $4350-4354$.

Trotter J, DeJong LJ, Smith ME (1986): Opsonization with antimyelin antibody increases the uptake and intracellular metabolism of myelin in inflammatory macrophages. J Neurochem 47:779789.

Wajgt A, Gorny M (1983): CSF antibodies to myelin basic protein and to myelin-associated glycoprotein in multiple sclerosis. Evidence of the intrathecal production of antibodies. Acta Neurol Scand 68:337-343.

Warren KG, Catz I (1986): Diagnostic value of cerebrospinal fluid anti-myelin basic protein in patients with multiple sclerosis. Ann Neurol 20:20-25.

Warren KG, Catz I (1987): A correlation between cerebrospinal fluid myelin basic protein and anti-myelin basic protein in multiple sclerosis patients. Ann Neurol 21:183-189.

Whitacre CC, Mattson DH, Paterson PY, Roos RP, Peterson DJ, Arnason BGW (1981): Cerebrospinal fluid and serum oligoclonal IgG bands in rabbits with experimental allergic encephalomyelitis. Neurochem Res 6:87-9.

Whitacre CC, Mattson DH, Day ED, Peterson DJ, Paterson PY, Roos RP, Arnason BGW (1982): Oligoclonal IgG in rabbits with experimental allergic encephalomyelitis: Non-reactivity of the bands with sensitizing neural antigens. Neurochem Res 7: 1209-1221. 